\title{
Rest tremor revisited: Parkinson's disease and other disorders
}

\author{
Wei Chen ${ }^{1,2}$, Franziska Hopfner ${ }^{2}$, Jos Steffen Becktepe ${ }^{2}$ and Günther Deuschl1, ${ }^{1 *}$
}

\begin{abstract}
Tremor is the most common movement disorder characterized by a rhythmical, involuntary oscillatory movement of a body part. Since distinct diseases can cause similar tremor manifestations and vice-versa, it is challenging to make an accurate diagnosis. This applies particularly for tremor at rest. This entity was only rarely studied in the past, although a multitude of clinical studies on prevalence and clinical features of tremor in Parkinson's disease (PD), essential tremor and dystonia, have been carried out. Monosymptomatic rest tremor has been further separated from tremor-dominated PD. Rest tremor is also found in dystonic tremor, essential tremor with a rest component, Holmes tremor and a few even rarer conditions. Dopamine transporter imaging and several electrophysiological methods provide additional clues for tremor differential diagnosis. New evidence from neuroimaging and electrophysiological studies has broadened our knowledge on the pathophysiology of Parkinsonian and non-Parkinsonian tremor. Large cohort studies are warranted in future to explore the nature course and biological basis of tremor in common tremor related disorders.
\end{abstract}

Keywords: Tremor, Parkinson's disease, Essential tremor, Dystonia, Pathophysiology

\section{Background}

Tremor is defined as a rhythmical, involuntary oscillatory movement of a body part [1]. Making an accurate diagnosis of tremor disorders is challenging, since similar clinical entities may be caused by different diseases. Due to the lack of biomarkers, misdiagnoses among parkinsonian tremor, essential tremor (ET) and dystonic tremor are not uncommon [2]. Generally, tremor may be evaluated by features of medical history (family history, onset age, and temporal evolution), tremor characteristics (topography, activation condition, frequency and amplitude) and associated systemic or neurological signs. Besides, ancillary tests (dopamine transporter imaging, electrophysiological evaluation, response to levodopa etc.) are needed for patients with undetermined tremor entities (Table 1).

The consensus statement of Movement Disorder Society (MDS) on tremor in 1998 constitutes the main clinical classification system for tremor, is widely accepted and has been followed in the past two decades [1]. Many studies have been conducted to explore the prevalence

\footnotetext{
*Correspondence: g.deuschl@neurologie.uni-kiel.de

'Department of Neurology, Shanghai Ninth People's Hospital affiliated to Shanghai Jiao Tong University School of Medicine, 200011 Shanghai, China 2Department of Neurology, Universitätsklinikum Schleswig-Holstein, Kiel Campus, Christian-Albrechts-University, Rosalind Franklinstr.10, 24105 Kiel, Germany
}

(c) The Author(s). 2017 Open Access This article is distributed under the terms of the Creative Commons Attribution 4.0 International License (http://creativecommons.org/licenses/by/4.0/), which permits unrestricted use, distribution, and reproduction in any medium, provided you give appropriate credit to the original author(s) and the source, provide a link to the Creative Commons license, and indicate if changes were made. The Creative Commons Public Domain Dedication waiver (http://creativecommons.org/publicdomain/zero/1.0/) applies to the data made available in this article, unless otherwise stated. and clinical correlates of tremor in common tremor related disorders. Some practical clinical cues and ancillary tests for clinical distinction are found [3]. Besides, accumulating structural and functional neuroimaging, as well as electrophysiological studies broaden our understanding on the pathophysiology of tremor in different kinds of movement disorders.

Therefore, the present review will mainly revisit the progress on prevalence and clinical features of rest tremor in Parkinson's disease (PD), ET and dystonia. For patients with monosymptomatic tremor at rest, the possible clinical outcomes are discussed. Also, the potential ancillary tests for tremor differential diagnosis and underlying pathophysiological basis of tremor in common tremor related disorders are debated.

\section{Tremor in Parkinson's disease Prevalence}

The epidemiology of tremor in PD has not yet been deeply studied. A case series of 100 pathologically proven PD revealed tremor in $68 \%$ of cases at disease onset, in $75 \%$ during the course of the disease, and in 9\%, tremor disappeared late in the course of the illness [4]. Rest tremor was noted at least during one evaluation among 47 pathologically verified Parkinsonian patients [5]. Action tremor 
Table 1 Key clinical features and pathophysiological basis of tremor in Parkinson's disease, essential tremor and dystonia

\begin{tabular}{|c|c|c|c|}
\hline & Parkinsonian tremor & Essential tremor & Dystonic tremor \\
\hline \multicolumn{4}{|l|}{ Key clinical features } \\
\hline Topography & Hand $>$ others & $\begin{array}{l}\text { Hands }>\text { head }>\text { voice }> \\
\text { others }\end{array}$ & head $>$ Hands $>$ others \\
\hline Activation condition & Rest $>$ postural/kinetic & Postural $>$ kinetic $>$ rest & Postural $>$ kinetic $>$ rest \\
\hline Symmetry & Asymmetrical & Symmetrical & Asymmetrical \\
\hline $\begin{array}{l}\text { Suppression of tremor during } \\
\text { movement onset }\end{array}$ & in most cases & not found & rare \\
\hline Frequency & $4-6 \mathrm{~Hz}$ & $4-8 \mathrm{~Hz}$ & $7 \mathrm{~Hz}$ \\
\hline Amplitude & Regular & Regular & Irregular \\
\hline Potential accompanying signs & Bradykinesia, rigidity, etc & Impaired tandem gait & Dystonic posture \\
\hline \multicolumn{4}{|l|}{ Possible pathophysiological basis } \\
\hline Triggering factor & $\begin{array}{l}\text { Dopaminergic dysfunction in } \\
\text { nigrostriatal system }\end{array}$ & $\begin{array}{l}\text { Reduced inhibition in } \\
\text { cerebellum and brainstem }\end{array}$ & $\begin{array}{l}\text { Reduced inhibitory reflex at } \\
\text { multiple levels } \\
\text { (spinal, brainstem, and cortical, etc.) }\end{array}$ \\
\hline Activated circuit & Cerebello-thalamo-cortical circuit & & \\
\hline
\end{tabular}

was reported in 46-93\% of PD patients depending on the selected populations $[6,7]$.

\section{Clinical features}

All different forms of tremor i.e. rest, postural or kinetic tremor may occur in patients with PD. The most common form, classical Parkinsonian rest tremor, refers to a 4- to $6-\mathrm{Hz}$ pill-rolling tremor in the fully resting limb, which is suppressed during movement initiation [8]. It can be provoked by stressful situations like backwards counting, tapping of the contralateral limb or by using the Stroop test. [9] The maximal amplitude is reached on average after 2-3 min [9]. As most motor symptoms of $\mathrm{PD}$, rest tremor is often more pronounced unilaterally, and the upper limbs are usually more affected than the legs. Besides extremities, rest tremor also occurs in the tongue, lip or chin, but rarely involves the head. Other types like postural and kinetic tremor may also occur in PD. It is reported that action tremor is associated with rest tremor in $\mathrm{PD}$, and appears more severely on the side of the body in which the rest tremor is predominant [6]. One of the most important diagnostic features is the suppression of rest tremor during movement onset [10]. Re-emergent tremor, defined as tremor slowly emerging when a new position of the extremity is acquired, is regarded as the same phenomenon when it is clinically more severely expressed [11].

Accumulating evidence indicates that tremor dominant PD is a distinct subtype from those with bradykinesia and rigidity. Clinically, tremor can even be worse on the opposite side of the more severe bradykinesia. Tremor dominant patients have higher dopamine transporter binding, compared to akinetic-rigid type [12], whereas tremor severity does not correlate with striatal dopamine deficits [13]. As demonstrated in DATATOP cohort, tremor dominant PD reported a less severe motor, cognition and functional disability than patients with postural instability and gait difficulty [14]. Prospective studies suggest that this subtype may predict a more favorable prognosis in terms of less mortality risk and lower probability of developing levodopa induced dyskinesia (LID) [15]. However, at later stages of the condition the course is similar for the akinetic-rigid variant and the tremor-dominant variant [16].

\section{Essential tremor \\ Prevalence}

The prevalence of ET ranges from $1 \%$ in the total population to $5 \%$ for those beyond the age of 60 years [17]. Regarding tremor localizations, arm tremor was reported in 90-100\%, head tremor was reported in $21-44 \%$; whereas voice tremor was found in $12-49 \%$ of ET. With respect to the conditions activating tremor, intention tremor (IT) occurs approximately in one third of ET cases [18]. Rest tremor was also noted in ET, its prevalence is highly dependent on the selected cohorts, ranging from as low as $2 \%$ in the population-based setting to $46 \%$ in the brain bank samples [19]. As a feature of ET, alcohol sensitivity was reported in at least $46 \%$ of the patients [20].

\section{Clinical features}

ET is a common movement disorder defined by sparse clinical criteria. The clinical hallmark of ET is an involuntary postural or kinetic tremor affecting mainly the hands and forearms in the absence of other neurological signs, in particular dystonia and clear-cut ataxia or bradykinesia [1]. In addition to classic postural tremor in ET, patients may also have IT and rest tremor. Head and 
voice tremor are regarded as the second and third common tremor localizations [21].

Accumulating evidence indicates that ET is not a single entity but a group of diseases with diverse etiologies most of which are currently unknown [22, 23]. However, it is unknown if there are clinical criteria which separate different conditions. One promising stratifying marker is age at onset. Most epidemiological studies of ET show two distinct age at onset peaks: early and late disease onset. Early-onset patients more frequently reported a positive family history and alcohol sensitivity of tremor [24], whereas late-onset patients have faster tremor progression, more frequent dementia and earlier mortality [25]. Another subgrouping may be possible on the basis of the topography of ET. Phenotypic differences were found among patients stratified by head and voice tremor condition [21]. Female gender is associated with head tremor in ET as shown in our latest meta-analysis [21]. Both female and severe hand tremor may increase the risk of head and/or voice tremor in ET [21]. Activation conditions may also be phenotypical features separating different entities [26, 27]. It has been reported that ET patients with IT were older and had more frequent head and trunk involvement [26]; whereas patients with rest tremor were also older and have longer disease duration and greater tremor severity [19]. Neuroimaging studies reported that ET with head tremor had more cerebellar atrophy, especially in the vermis of the anterior lobe $[28,29]$. Also, a recent pathological study found that patients with head and voice tremors had more Purkinje cell axonal swellings with torpedoes in the cerebellar vermis [30].

\section{Tremor in dystonia}

Tremor has been recognized as an important clinical feature in dystonia. According to the consensus classification of tremor in 1998, tremor in dystonia may be classified into 1): dystonic tremor (DT), with tremor in the same body parts by dystonia, 2) tremor associated with dystonia (TAWD), with tremor in the unaffected regions of dystonia, and 3) dystonia gene-associated tremor [1].

\section{Prevalence}

There is a wide variability of tremor prevalence in dystonia, ranging from 14 to $87 \%$, due to selected cases and the sample size [31, 32]. So far, the largest case series found that $262(55 \%)$ out of 473 adult-onset primary dystonia showed tremor as a main symptom, with head tremor being the most common affected location $(n=196,41 \%)$, followed by hand tremor $(n=140$, 30\%) [33]. Among 140 patients with arm tremor, all presented postural tremor, 103 patients $(73.6 \%)$ presented a kinetic component, whereas 57 patients (40.7\%) also had rest tremor [33].

\section{Clinical features}

Tremor occurs at, before or after the onset of dystonia. Tremor in dystonia is usually postural or kinetic but rest tremor can also be found [33]. Topographically, most studies reported a greater occurrence for head tremor than for upper limb tremor, whereas voice and leg tremor were considerably rare [31].

Accumulating observational studies indicated that some phenotypic parameters including gender, age at onset, localizations of dystonia, may influence the status of tremor in dystonia. Data on gender distribution in tremor of dystonia indicated a female to male predominance ranging from 1.2:1 to 3.7:1 [31]. Rest tremor was noted more frequent in patients with late-onset dystonia than in those with early-onset dystonia [34]. Based on two large cohorts with dystonia [33, 35], patients with segmental, multifocal and generalized dystonia had a higher proportion of tremor relative to focal dystonia. Among subgroups patients with focal dystonia, both studies showed a greater tremor occurrence in patients with cervical dystonia than in those with blepharospasm and task-specific upper limb dystonia.

Apart from the clinical characteristics, genetic factors may also contribute to the occurrence of tremor in dystonia. Pathogenic mutations in the anoctamin 3 gene (ANO3) were identified to cause autosomal dominant craniocervical dystonia and have been assigned to the dystonia locus dystonia-24 (DYT24) [36]. It was reported the presence of tremor was the characteristic feature in all affected individuals. In some individuals with $A N O 3$ mutations, tremor was the sole initial manifestation leading to the misdiagnosis of ET [37, 38]. Head tremor was also noted in DYT25 patients with guanine nucleotide-binding protein(GNAL) mutation [39].

\section{Monosymptomatic rest tremor (mRT)}

A diagnostic challenge comes from patients presenting with predominant rest tremor without unequivocal bradykinesia or rigidity. According to MDS consensus statement on tremor in 1998, 'monosymptomatic rest tremor' $(\mathrm{mRT})$ was used if these patients had a tremor duration of at least 2 years [1]. Since rest tremor is a classic sign of PD, this entity of patients was also labelled as 'benign tremulous Parkinsonism'(BTP) in some previous clinical studies [40, 41].

There is still a debate on the etiology of $\mathrm{mRT}$ and its relation to PD. An early study indicated that patients with $\mathrm{mRT}$ had a nearly identical striatal dopaminergic deficit as in PD [42]. The majority of these patients with mRT will develop PD after a decade or more [43]. But they can also have ET with a rest component, dystonic tremor, Holmes tremor or a few even rarer conditions [43] (Fig. 1). If PD is the cause of mRT patients, this can be proven in-vivo with dopamine transporter (DAT) 


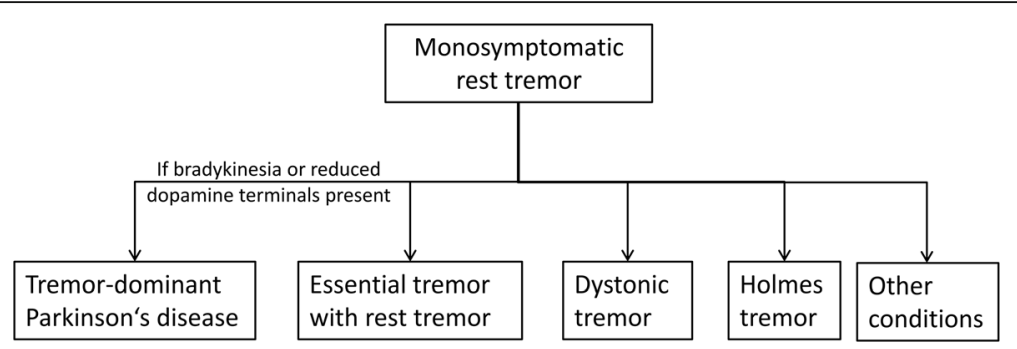

Fig. 1 Diagnostic outcome of monosymptomatic rest tremor. (Deuschl G. Mov Disord.2013 [43])

imaging. A recent prospective study found that 28 out of 33 patients with mRT developed PD verified by DAT positron emission tomography (DAT-PET), whereas 5 cases (15\%) have scans without evidence of dopaminergic deficits (SWEDDs) [44]. An important pathological study came from 21 patients with the initial presentation of $\mathrm{mRT}$ (labeled by the authors as BTP). At postmortem, 16 of them fulfilled the neuropathological criteria of PD, 5 cases (24\%) didn't have nigral impairment and were diagnosed as ET with associated rest tremor or dystonic tremor [45]. These reports also provide a good argument for replacing the term 'BTP' by ' $\mathrm{mRT}$ ' in the literature, as some of these cases never develop PD and if they do, the course is not benign [43].

\section{Ancillary tests for tremor differential diagnoses}

The overlap among tremor disorders is wide and complex. ET patients may present postural tremor coexisting with resting tremor, while postural tremor may coexist with resting tremor in $\mathrm{PD}$ and tremor in dystonia is often mixed including a rest tremor component. For the most complicated tremor patients, Dopamine transporter imaging (DATScan) can provide objective evidence to demonstrate presynaptic nigrostriatal dopaminergic deficit in PD, whereas, it is normal in essential, dystonic and psychogenic tremor.

Several electrophysiological tests also showed the potential value for the clinical distinction [46] (Table 2). One method is based on quantified analysis of forearm electromyography (EMG) and accelerometry. Advanced mathematical techniques, in this case the 'mean harmonic power, using these data have shown to be a useful measure to separate clinically difficult cases of advanced ET from tremulous PD, and the accuracy is up to $94 \%$ [47]. As one of the most common functional movement disorders, psychogenic tremor (PT) can present with all kinds of tremor type with variable tremor frequency and severity. The key clinical features that help to differentiate psychogenic from organic tremor are a sudden tremor onset, unusual disease course, often with fluctuations or remissions, distractibility of the tremor if attention is removed from the affected body part, tremor entrainment, tremor variability, and a coactivation sign
[48]. In cases where the clinical diagnosis remains challenging, providing a "laboratory-supported" level of certainty aids an early positive diagnosis [49]. Due to the inability of a patient with PT to generate voluntary tapping oscillations independent of their ongoing tremor oscillation, coherence entrainment test (CET) was used as a sensitive and specific means to distinguish PT from dystonic and other organic tremors, with nearly $100 \%$ concordance with clinical diagnosis [50]. Another method is blink reflex technique reflecting the brainstem excitability. Increased R2 recovery index was found in dystonic tremor, whereas it is within the normal range in ET, with $100 \%$ accuracy [51]. Regarding the interstimulus intervals (ISI) of $100 \mathrm{~ms}$, this method also seems to be reliable (100\% accuracy) for the distinction of Parkinsonian from essential tremor [52]. The third promising technique comes from sensory function tests. It is reported that temporal discrimination movement threshold (TDMT) is higher in ET, in contrast to dystonic tremor with increased somatosensory temporal discrimination threshold (TDT) [53]. Reduced reciprocal inhibition (RI) of arm muscles assessed with an H-reflex technique was found to be abnormal in patients with early onset of arm tremor and later development of torticollis, but ET had normal presynaptic inhibition [54]. Patients with a late and simultaneous onset of arm tremor and torticollis had normal RI [54]. This is put forward as an argument that dystonic tremor and tremor in dystonia do not necessarily share the same pathophysiological mechanism.

\section{Pathophysiology of Parkinsonian and non- Parkinsonian tremor}

It is assumed that tremor networks within the brain are responsible for the different tremors. These circuits are not yet precisely known. Some nodes seem to play an important role. Ventral intermediate nucleus (Vim) of the thalamus is the relay site in cerebellar outflow pathway where deep brain stimulation (DBS) can improve almost all tremors (PD, ET and dystonia) indicating that cerebellum and its outflow pathway may involve in tremor genesis [55] (Table 1). 


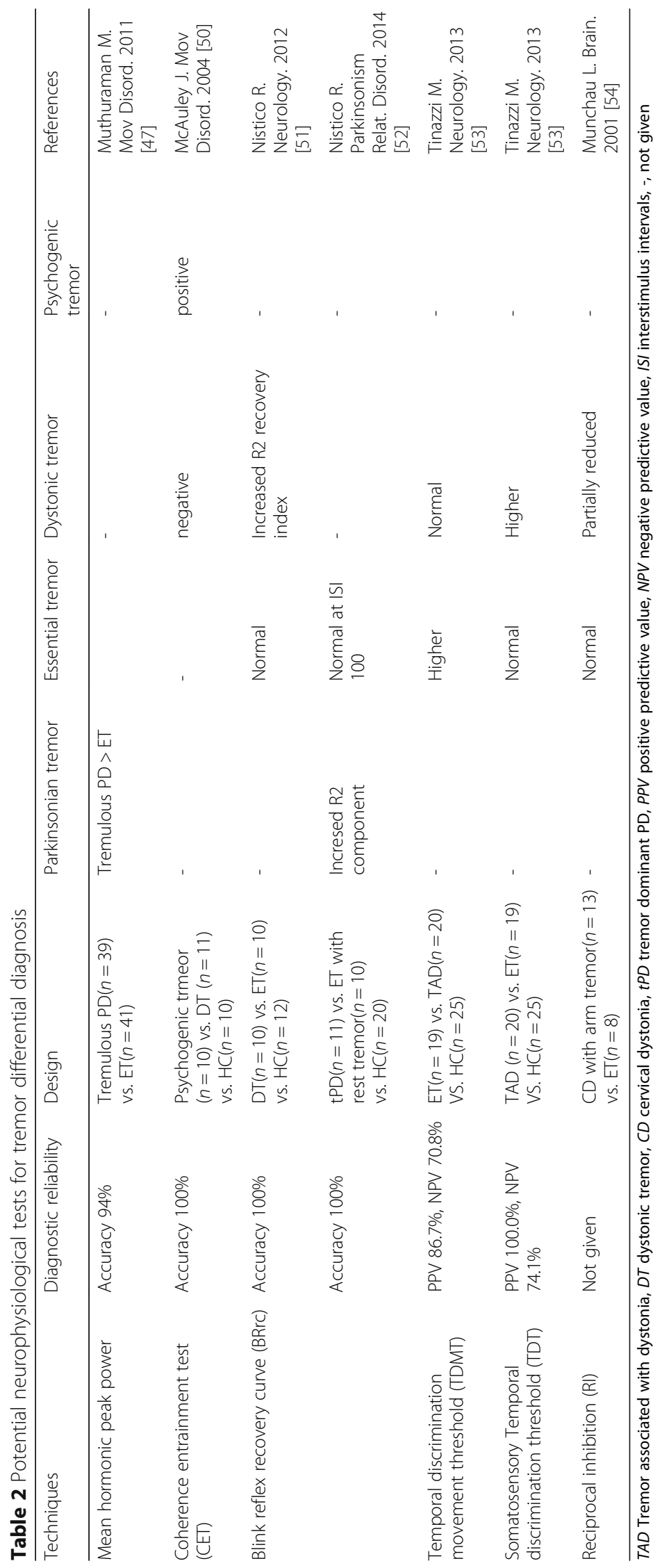


Emerging neuroimaging evidence showed that both the basal ganglia and the cerebellum are involved in Parkinsonian tremor [56]. It was reported that PD with rest tremor had more grey matter volume decrease in the right quadrangular lobe and declive of the cerebellum [57] and more iron accumulation in dentate nucleus, relative to those with akinetic-rigid type [58]. Data from functional neuroimaging indicates that dopaminergic dysfunction in pallidum triggers the onset of tremor, whereas, the tremor amplitude is regulated within the cerebello-thalamocortical circuit [59].

Theories on the pathophysiology of ET include the neurodegenerative, GABAergic and oscillatory network hypotheses [60]. For patients with ET, there is no postmortem gold standard for histopathological confirmation of the diagnosis, as it is in PD [61]. Limited pathological and neurochemical studies point to cerebellum and brainstem abnormalities in ET, including cerebellar Purkinje cell loss, axonal swellings (torpedoes) [62], as well as GABAergic dysfunction of the dentate nucleus in the cerebellum [63] and locus coeruleus in the brainstem [64]. The methodology beetwen different reseach groups investigating the pathology of ET diverge Torpedo cells, so-called Torpedoes were found only by one rearch group [62]. Other features like Purkinje cell loss in one study [65] cannot be confirmed by others [66]. Advanced neuroimaging provides an alternative way to understand the mechanism and networks involved in ET. A PET study indicated that ET is associated with reduced GABAergic function and increased binding of GABA receptor sites in brain regions implicated specifically in tremor genesis [67]. A recent study combining voxel-based morphometry, tractography and resting-state functional MRI suggests that a primary cerebellar defect leads to the emergence of a pathological oscillation which sets the tremor frequency, but the clinical manifestation of tremor is dependent on the cortical output [68].

Available electrophysiological studies demonstrate that patients with dystonia and tremor had reduced reciprocal inhibition between agonist and antagonist of upper limb muscles, a lack of brainstem interneuronal inhibition (BRrc), and abnormal sensory integration (TDT), indicating a lack of inhibitory mechanism at multiple levels (spinal, brainstem, and cortical) [31]. The neurophysiologic abnormalities in patients with dystonia and tremor resemble those in dystonia but differ from those described in ET, indicating tremor as phenotypic feature of dystonia. It has further been hypothesized that tremor in dystonia was caused by distorted cerebellar output due to abnormal burst firing pattern in Purkinje cells [31]. Structural MRI found that 27 (14\%) of 188 dystonia cases had cerebellar atrophy or cerebellar lesions [69] whereas functional neuroimaging studies on tremor in dystonia are lacking.

\section{Conclusions}

A series of epidemiological studies have yielded variable tremor prevalence among PD, ET and dystonia. These discrepancies may be partly due to sample selection as well as different definitions for rest tremor in parkinsonian tremor, ET and dystonic tremor and their subtypes. A diagnostic challenge comes from patients with mRT. Besides key clinical phenotypic differences and DAT scan, several transducer-based techniques like accelerometry, gyroscopy, EMG, and digitizing tablet-based meaures may provide extra clues for the distinction [70]. Compared to rating scales, these transducers are far more sensitive to changes in tremor amplitude and frequency. However, due to the natural variability of tremor, they are not more sensitive in defining the minimal detectable change than rating scales [70]. Also, their potential diagnostic values (sensitivity and specificity) still merit further validation in larger cohort studies. More studies on the pathophysiology of the different tremor entities are needed, which may help to develop new diagnostic markers and hence a more tailored therapeutic strategy. Studies on the natural course and biological basis of tremor are still warranted with standardized terminology, diagnostic criteria, validated evaluation tools and research protocols.

\section{Abbreviations \\ ANO3: Anoctamin 3 gene; BRrc: Brainstem interneuronal inhibition; BTP: Benign tremulous Parkinsonism; CET: Coherence entrainment test; DAT: Dopamine transporter; DBS: Deep brain stimulation; DT: Dystonic tremor; DYT24: Dystonia locus dystonia-24; EMG: Electromyography; ET: Essential tremor; GNAL: Guanine nucleotide-binding protein; IT: Intention tremor; LID: Levodopa induced dyskinesia; MDS: Movement disorder society; mRT: Monosymptomatic rest tremor; PD: Parkinson's disease; PT: Psychogenic tremor; SWEDDs: Scans without evidence of dopaminergic deficits; TAWD: Tremor associated with dystonia; TDMT: Temporal discrimination movement threshold; TDT: Temporal discrimination threshold; Vim: Ventral intermediate nucleus}

\section{Acknowledgements}

Not applicable.

\section{Funding}

Wei Chen received grants from Youth Fund of Shanghai Ninth People's Hospital, K.C.Wong Medical Fund of Shanghai Jiao Tong University, and National Natural Science Fund of China (81401039). Franziska Hopfner received grants from the German Research Council (DFG), the International Essential Tremor Foundation (IETF) and the medical faculty of the ChristianAlbrechts-University Kiel. Günther Deuschl received grants from the German Research Council (DFG), the German Ministry of Education and Health. Jos Steffen Becktepe reports no disclosures.

\section{Availability of data and materials Not applicable.}

\section{Authors' contributions}

GD conceived the study, gave suggestions on writing and revised the article. WC acquired the data, drafted the review. FH gave suggestions on organizing the materials and revised the manuscript. JSB gave comments on the content of the manuscript. All authors read and approved the final manuscript. 


\section{Competing interests}

The authors declare that they have no competing interests.

\section{Consent for publication}

Not applicable.

Ethics approval and consent to participate

Not applicable.

\section{Publisher's Note}

Springer Nature remains neutral with regard to jurisdictional claims in published maps and institutional affiliations.

Received: 13 March 2017 Accepted: 6 June 2017

Published online: 16 June 2017

\section{References}

1. Deuschl G, Bain P, Brin M. Consensus statement of the movement disorder society on tremor. Ad Hoc Sci Committee Mov Disord. 1998:13 Suppl 3:2-23

2. Jain $\mathrm{S}$, Lo SE, Louis ED. Common misdiagnosis of a common neurological disorder: how are we misdiagnosing essential tremor? Arch Neurol. 2006:63:1100-4.

3. Gövert F, Deuschl G. Tremor entities and their classification: an update. Curr Opin Neurol. 2015:28:393-9.

4. Hughes AJ, Daniel SE, Blankson S, Lees AJ. A clinicopathologic study of 100 cases of Parkinson's disease. Arch Neurol. 1993:50:140-8.

5. Rajput AH, Rozdilsky B, Ang L. Occurrence of resting tremor in Parkinson's disease. Neurology. 1991:41:1298-9.

6. Louis ED, Levy G, Côte L, Mejia H, Fahn S, Marder K. Clinical correlates of action tremor in Parkinson disease. Arch Neurol. 2001;58:1630-4.

7. Gigante AF, Bruno G, lliceto G, Guido M, Liuzzi D, Mancino PV, et al. Action tremor in Parkinson's disease: frequency and relationship to motor and non-motor signs. Eur J Neurol. 2015;22:223-8.

8. Deuschl G, Papengut F, Hellriegel H. The phenomenology of parkinsonian tremor. Parkinsonism Relat Disord. 2012;18 Suppl 1:S87-89.

9. Raethjen J, Austermann K, Witt K, Zeuner KE, Papengut F, Deuschl G. Provocation of Parkinsonian tremor. Mov Disord. 2008:23:1019-23.

10. Papengut F, Raethjen J, Binder A, Deuschl G. Rest tremor suppression may separate essential from parkinsonian rest tremor. Parkinsonism Relat Disord. 2013:19:693-7.

11. Jankovic J, Schwartz KS, Ondo W. Re-emergent tremor of Parkinson's disease. J Neurol Neurosurg Psychiatry. 1999:67:646-50.

12. Spiegel J, Hellwig D, Samnick S, Jost W, Möllers M-O, Fassbender K, et al. Striatal FP-CIT uptake differs in the subtypes of early Parkinson's disease. J Neural Transm. 2007;114:331-5. 1996.

13. Rossi C, Frosini D, Volterrani D, De Feo $P$, Unti E, Nicoletti $V$, et al. Differences in nigro-striatal impairment in clinical variants of early Parkinson's disease: evidence from a FP-CIT SPECT study. Eur J Neurol. 2010;17:626-30

14. Jankovic J, McDermott M, Carter J, Gauthier S, Goetz C, Golbe L, et al. Variable expression of Parkinson's disease: a base-line analysis of the DATATOP cohort. The Parkinson study group. Neurology. 1990;40:1529-34.

15. Kipfer S, Stephan MA, Schüpbach WMM, Ballinari P, Kaelin-Lang A. Resting tremor in Parkinson disease: a negative predictor of levodopa-induced dyskinesia. Arch Neurol. 2011;68:1037-9.

16. Selikhova M, Williams DR, Kempster PA, Holton JL, Revesz T, Lees AJ. A clinico-pathological study of subtypes in Parkinson's disease. Brain. 2009;132:2947-57.

17. Louis ED, Ottman R, Hauser WA. How common is the most common adult movement disorder? estimates of the prevalence of essential tremor throughout the world. Mov Disord. 1998;13:5-10.

18. Louis ED, Frucht SJ, Rios E. Intention tremor in essential tremor: Prevalence and association with disease duration. Mov Disord. 2009;24:626-7.

19. Louis ED, Hernandez N, Michalec M. Prevalence and correlates of rest tremor in essential tremor: cross-sectional survey of 831 patients across four distinct cohorts. Eur J Neurol. 2015;22:927-32.

20. Hopfner F, Erhart T, Knudsen K, Lorenz D, Schneider SA, Zeuner KE, et al. Testing for alcohol sensitivity of tremor amplitude in a large cohort with essential tremor. Parkinsonism Relat Disord. 2015;21:848-51.
21. Chen W, Hopfner F, Szymczak S, Granert O, Müller SH, Kuhlenbäumer G, et al. Topography of essential tremor. Parkinsonism Relat. Disord. 2017. doi: 10. 1016/j.parkreldis.2017.04.012.

22. Marsden C, Obeso J, Rothwell J. Benign essential tremor is not a single entity. In: Yahr MD, editor. Curr. Concepts park. Dis. Relat. Disord. Amsterdam: Excerpta Medica; 1983. p. 31-46.

23. Louis ED. "Essential tremor" or "the essential tremors": is this one disease or a family of diseases? Neuroepidemiology. 2014;42:81-9.

24. Hopfner F, Ahlf A, Lorenz D, Klebe S, Zeuner KE, Kuhlenbäumer G, et al. Early- and late-onset essential tremor patients represent clinically distinct subgroups. Mov Disord. 2016;31:1560-6.

25. Deuschl G, Petersen I, Lorenz D, Christensen K. Tremor in the elderly: essential and aging-related tremor. Mov Disord. 2015;30:1327-34.

26. Deuschl G, Wenzelburger R, Löffler K, Raethjen J, Stolze H. Essential tremor and cerebellar dysfunction clinical and kinematic analysis of intention tremor. Brain. 2000;123(Pt 8):1568-80

27. Cohen O, Pullman S, Jurewicz E, Watner D, Louis ED. Rest tremor in patients with essential tremor: prevalence, clinical correlates, and electrophysiologic characteristics. Arch. Neurol. 2003:60:405-10.

28. Quattrone A, Cerasa A, Messina D, Nicoletti G, Hagberg GE, Lemieux L, et al. Essential head tremor is associated with cerebellar vermis atrophy: a volumetric and voxel-based morphometry MR imaging study. AJNR. 2008;29:1692-7.

29. Cerasa A, Messina D, Nicoletti G, Novellino F, Lanza P, Condino F, et al. Cerebellar atrophy in essential tremor using an automated segmentation method. AJNR. 2009:30:1240-3.

30. Louis ED, Faust PL, Ma KJ, Yu M, Cortes E, Vonsattel J-PG. Torpedoes in the cerebellar vermis in essential tremor cases vs. controls. Cerebellum. 2011:10:812-9.

31. Defazio G, Conte A, Gigante AF, Fabbrini G, Berardelli A. Is tremor in dystonia a phenotypic feature of dystonia? Neurology. 2015:84:1053-9.

32. Pandey S, Sarma N. Tremor in dystonia. Parkinsonism Relat Disord. 2016;29:3-9.

33. Erro R, Rubio-Agusti I, Saifee TA, Cordivari C, Ganos C, Batla A, et al. Rest and other types of tremor in adult-onset primary dystonia. J Neurol Neurosurg Psychiatry. 2014;85:965-8.

34. Gigante AF, Berardelli A, Defazio G. Rest tremor in idiopathic adult-onset dystonia. Eur J Neurol. 2016;23:935-9.

35. Defazio G, Gigante AF, Abbruzzese G, Bentivoglio AR, Colosimo C, Esposito M, et al. Tremor in primary adult-onset dystonia: prevalence and associated clinical features. J Neurol Neurosurg Psychiatry. 2013;84:404-8.

36. Charlesworth G, Plagnol V, Holmström KM, Bras J, Sheerin U-M, Preza E, et al. Mutations in $\mathrm{ANO} 3$ cause dominant craniocervical dystonia: ion channel implicated in pathogenesis. Am J Hum Genet. 2012;91:1041-50

37. Hopfner F, Bungeroth M, Pendziwiat M, Tittmann L, Deuschl G, Schneider SA, et al. Rare variants in $\mathrm{ANO} 3$ are not a susceptibility factor in essential tremor. Parkinsonism Relat Disord. 2014;20:134-5.

38. Stamelou M, Charlesworth G, Cordivari C, Schneider SA, Kägi G, Sheerin U-M, et al. The phenotypic spectrum of DYT24 due to ANO3 mutations. Mov Disord. 2014;29:928-34.

39. Fuchs T, Saunders-Pullman R, Masuho I, Luciano MS, Raymond D, Factor S, et al. Mutations in GNAL cause primary torsion dystonia. Nat Genet. 2013;45:88-92.

40. Josephs KA, Matsumoto JY, Ahlskog JE. Benign tremulous parkinsonism. Arch Neurol. 2006:63:354-7.

41. Deeb W, Hu W, Almeida L, Patterson A, Martinez-Ramirez D, Wagle SA. Benign tremulous Parkinsonism: a unique entity or another facet of Parkinson's disease? Transl Neurodegener. 2016;5:10.

42. Ghaemi M, Raethjen J, Hilker R, Rudolf J, Sobesky J, Deuschl G, et al. Monosymptomatic resting tremor and Parkinson's disease: a multitracer positron emission tomographic study. Mov Disord. 2002;17:782-8.

43. Deuschl G. Benign tremulous Parkinson's disease: a misnomer? Mov Disord. 2013:28:117-9.

44. Zheng H-G, Zhang R, Li X, Li F-F, Wang Y-C, Wang X-M, et al. Heterogeneity of monosymptomatic resting tremor in a prospective study: clinical features, electrophysiological test, and dopamine transporter positron emission tomography. Chin Med J (Engl). 2015;128:1765-71.

45. Selikhova M, Kempster PA, Revesz T, Holton JL, Lees AJ. Neuropathological findings in benign tremulous parkinsonism. Mov Disord. 2013;28:145-52.

46. van der Stouwe AMM, Elting JW, van der Hoeven JH, van Laar T, Leenders KL, Maurits NM, et al. How typical are "typical" tremor characteristics? sensitivity and specificity of five tremor phenomena. Parkinsonism Relat Disord. 2016;30:23-8. 
47. Muthuraman M, Hossen A, Heute U, Deuschl G, Raethjen J. A new diagnostic test to distinguish tremulous Parkinson's disease from advanced essential tremor. Mov Disord. 2011;26:1548-52.

48. Schwingenschuh P, Deuschl G. Functional tremor. Handb Clin Neurol. 2016;139:229-33.

49. Schwingenschuh P, Saifee TA, Katschnig-Winter P, Macerollo A, KoeglWallner M, Culea V, et al. Validation of "laboratory-supported" criteria for functional (psychogenic) tremor. Mov Disord. 2016;31:555-62.

50. McAuley J, Rothwell J. Identification of psychogenic, dystonic, and other organic tremors by a coherence entrainment test. Mov Disord. 2004;19:253-67.

51. Nisticò R, Pirritano D, Salsone M, Valentino P, Novellino F, Condino F, et al. Blink reflex recovery cycle in patients with dystonic tremor: a cross-sectional study. Neurology. 2012;78:1363-5.

52. Nisticò R, Salsone M, Vescio B, Morelli M, Trotta M, Barbagallo G, et al. Blink reflex recovery cycle distinguishes essential tremor with resting tremor from de novo Parkinson's disease: an exploratory study. Parkinsonism Relat Disord. 2014;20:153-6.

53. Tinazzi M, Fasano A, Di Matteo A, Conte A, Bove F, Bovi T, et al. Temporal discrimination in patients with dystonia and tremor and patients with essential tremor. Neurology. 2013;80:76-84.

54. Münchau A, Schrag A, Chuang C, MacKinnon CD, Bhatia KP, Quinn NP, et al. Arm tremor in cervical dystonia differs from essential tremor and can be classified by onset age and spread of symptoms. Brain. 2001;124:1765-76.

55. Hallett M. Tremor: pathophysiology. Parkinsonism relat. Disord. 2014;20 Suppl 1:S118-122.

56. Hallett M. Parkinson's disease tremor: pathophysiology. Parkinsonism relat. Disord. 2012;18 Suppl 1:S85-86.

57. Benninger DH, Thees S, Kollias SS, Bassetti CL, Waldvogel D. Morphological differences in Parkinson's disease with and without rest tremor. J Neurol. 2009;256:256-63.

58. He N, Huang P, Ling H, Langley J, Liu C, Ding B, et al. Dentate nucleus iron deposition is a potential biomarker for tremor-dominant Parkinson's disease. NMR Biomed. 2017. doi:10.1002/nbm.3554.

59. Helmich RC, Janssen MJR, Oyen WJG, Bloem BR, Toni I. Pallidal dysfunction drives a cerebellothalamic circuit into Parkinson tremor. Ann Neurol. 2011;69:269-81.

60. Gövert F, Becktepe JS, Deuschl G. Current concepts of essential tremor. Rev Neurol. 2016:172:416-22.

61. Braak H, Del Tredici K, Rüb U, de Vos RAl, Jansen Steur ENH, Braak E. Staging of brain pathology related to sporadic Parkinson's disease. Neurobiol Aging. 2003;24:197-211.

62. Louis ED, Faust PL, Vonsattel J-PG, Honig LS, Rajput A, Robinson CA, et al. Neuropathological changes in essential tremor: 33 cases compared with 21 controls. Brain. 2007;130:3297-307.

63. Paris-Robidas $S$, Brochu E, Sintes M, Emond V, Bousquet M, Vandal M, et al. Defective dentate nucleus GABA receptors in essential tremor. Brain. 2012:135:105-16

64. Shill HA, Adler CH, Beach TG, Lue L-F, Caviness JN, Sabbagh MN, et al. Brain biochemistry in autopsied patients with essential tremor. Mov Disord. 2012;27:113-7

65. Louis ED, Lee M, Babij R, Ma K, Cortés E, Vonsattel J-PG, et al. Reduced Purkinje cell dendritic arborization and loss of dendritic spines in essential tremor. Brain. 2014;137:3142-8.

66. Rajput AH, Robinson CA, Rajput ML, Robinson SL, Rajput A. Essential tremor is not dependent upon cerebellar Purkinje cell loss. Parkinsonism Relat Disord. 2012;18:626-8

67. Boecker H, Weindl A, Brooks DJ, Ceballos-Baumann AO, Liedtke C, Miederer M, et al. GABAergic dysfunction in essential tremor: an 11C-flumazenil PET study. J Nucl Med. 2010;51:1030-5.

68. Gallea C, Popa T, García-Lorenzo D, Valabregue R, Legrand A-P, Marais L, et al. Intrinsic signature of essential tremor in the cerebello-frontal network. Brain. 2015;138:2920-33.

69. Batla A, Sánchez MC, Erro R, Ganos C, Stamelou M, Balint B, et al. The role of cerebellum in patients with late onset cervical/segmental dystonia?evidence from the clinic. Parkinsonism Relat Disord. 2015;21:1317-22.

70. Haubenberger D, Abbruzzese G, Bain PG, Bajaj N, Benito-León J, Bhatia KP, et al. Transducer-based evaluation of tremor. Mov Disord. 2016:31:1327-36.

\section{Submit your next manuscript to BioMed Central and we will help you at every step:}

- We accept pre-submission inquiries

- Our selector tool helps you to find the most relevant journal

- We provide round the clock customer support

- Convenient online submission

- Thorough peer review

- Inclusion in PubMed and all major indexing services

- Maximum visibility for your research

Submit your manuscript at www.biomedcentral.com/submit
Biomed Central 